\title{
MIXED TWO SIDED COMPLETE CHAIN SAMPLING PLANS FOR
}

\author{
MAXIMUM ALLOWABLE VARIANCE \\ K. REBECCA JEBASEELI EDNA \& V. JEMMY JOYCE \\ Department of Mathematics, Karunya Institute of Technology and Sciences (Deemed to be University),
}

Coimbatore, Tamil Nadu, India

\begin{abstract}
In acceptance sampling plans, mean is commonly used for variable inspection in the production field. In some situations, the variance of the quality characteristics is used as the criterion. That is, a lot may be accepted, if the variance of the quality characteristics is less than or equal to a pre-specified maximum $\left(\sigma_{o}{ }^{2}\right)$ value. In this paper, the operating procedure of Mixed Acceptance Sampling Plans with Maximum Allowable Variance is developed. Two-Sided Complete Chain Sampling plan are used in the second stage of mixed plans The Operating Characteristic function and other associated measures of the plan are given. The algorithm and designing of the mixed sampling plan is indexed through AQL and LQL. Tables are constructed for easy selection of the plan. An example is also provided.

KEYWORDS: Mixed Sampling, OC (operating characteristic) function, AQL(Acceptable Quality Level), LQL (Limiting Quality Level) I stage Sampling \& II stage Sampling
\end{abstract}

Received: Apr 06, 2018; Accepted: Apr 26, 2018; Published: May 22, 2018; Paper Id.: IJMPERDJUN201864

\section{INTRODUCTION}

Mixed Sampling Plan was introduced by Dodge and later Schilling (1967) has given a procedure to find the OC function and its associated measures. Mixed Sampling Plan has two stages. The first stage is based on variable criteria and the second stage with attribute quality characteristics. In a Mixed Sampling Plans, the second stage of attribute inspection becomes more important to discriminate the lot, if the first stage variable inspection fails to accept the lot. In the second stage, acceptance number of zero plans is more significant for a practical reason. Therefore, two-sided complete chain sampling plans are used in the second stage. The resulting plans yield small samples in both the stages. Clark. C. R (1955), Frishman and Fred (1960), Dodge. H. F and Stephens K. S (1966), Kuralmani. V and Govindaraju. K (1993) contributed more to chain sampling plan. Suresh and Deva Arul (2002) have developed mixed sampling plans by combining process and product quality characteristics to reduce the sampling cost... Suresh and DevaArul (2003) have developed mixed sampling plans for Maximum Allowable Variance.

\section{FORMULATION AND OPERATING PROCEDURE OF MIXED PLAN WITH VARIANCE CRITERION}

The development of mixed plans and the subsequent discussions are limited only to the known variance $\left(\sigma^{2}\right)$. The mixed sampling plan with variance criterion can be formulated with four parameters $\mathrm{n}_{1}, \mathrm{n}_{2}, \mathrm{k}$, c. For predetermined values of the parameters, an independent plan with known variance would be carried out as follows: 
Step 1: Determine the four parameters, usually with reference OC curve.

Step 2: Draw a random sample of size $n_{1}$ from the lot assumed to be large.

Step 3: If the sample ratio $\frac{s^{2}}{\sigma_{0}^{2}} \leq k^{\prime}$, accept the lot.

Step 4: If the ratio $\frac{s^{2}}{\sigma_{0}^{2}}>k^{\prime}$, take another sample of size $\mathrm{n}_{2}$. Let it be the second stage.

Step 5: Inspect and count the number of defectives 'd' in the second stage.

- Accept the lot, if $d$ (the observed number of defectives) is zero in the sample of $\mathrm{n}_{2}$ units and reject if $\mathrm{d}>1$.

- Accept the lot, if $\mathrm{d}=1$ and if no defectives are found in the immediately preceding ' $\mathrm{i}$ ' samples and succeeding 'j' samples of size $n_{2}$.

\section{MEASURES OF THE INDEPENDENT MIXED SAMPLING PLANS}

Probability of Acceptance

$P_{a}(p)=P_{n_{1}}(\bar{x} \leq A)+P_{n_{1}}(\bar{x}>A) P_{0}^{i} P_{1} P_{0}^{j}$, where $P_{0}=e^{-n_{2} p}$ and $P_{1}=n_{2} p e^{-n_{2} p}$

Hence $P_{a}(p)=P_{n 1}\left[\left(\frac{s^{2}}{\sigma_{0}^{2}} \leq k^{\prime}\right)\right]+P_{n 1}\left[\left(\frac{s^{2}}{\sigma_{0}^{2}}>k^{\prime}\right)\right] e^{-n_{2} p}\left\{1+n_{2} p e^{-2 i n_{2} p}\right\}$, if $i=j$

Average Sample Number $\mathrm{ASN}=n_{1}+n_{2} P_{n 1}\left[\left(\frac{s^{2}}{\sigma_{0}^{2}} \leq k^{\prime}\right)\right]$

Average Total Inspection ATI $=\mathrm{ASN}+\left(\mathrm{N}-\mathrm{n}_{1}-\mathrm{n}_{2}\right)\left(1-\mathrm{P}_{\mathrm{a}}(\mathrm{p})\right)$

Average Outgoing Quality $A O Q=p . P_{a}(p)$ for any lot of large size

\section{DESIGNING MIXED SAMPLING PLAN INDEXED THROUGH AQL AND LQL}

- Assume that the plan is to be independent.

- Split the probability of acceptance that will be assigned to the first stage. Call these as $\beta_{1}$ 'and $\beta_{2}$ ' respectively. Note that $\beta_{1} \geq \beta_{1}$, and $\beta_{2} \geq \beta_{2}$ '.

- Use the standard variable procedure, determine the first sample size $\mathrm{n}_{1}$ as

$$
n_{1}=\left[\frac{Z\left(\beta_{2}{ }^{1}\right)-Z\left(\beta_{1}^{1}\right)}{Z\left(p_{1}\right)-Z\left(p_{2}\right)}\right]^{2}
$$

- Then the acceptance limit is

$$
\alpha=P\left(\frac{S^{2}}{\sigma_{0}^{2}}>k^{\prime}\right)=\int_{\frac{k^{\prime}}{\lambda}}^{\infty} f(z) d z
$$


- Now determine the probability of them acceptance associated with $\mathrm{p}_{1}$ and $\mathrm{p}_{2}$ respectively. Let them be $\beta_{1}$ " and $\beta_{2}$ "

$$
\begin{aligned}
& \beta_{1}{ }^{\prime \prime}=\frac{\beta_{1}-\beta_{1}{ }^{1}}{1-\beta_{1}{ }^{1}} \\
& \beta_{2}{ }^{\prime \prime}=\frac{\beta_{2}-\beta_{2}{ }^{\prime}}{1-\beta_{2}{ }^{\prime}}
\end{aligned}
$$

- Determine the appropriate second sample size $\mathrm{n} 2$ for the given index $\mathrm{i}$ and $\mathrm{j}$

$$
\text { such that } e^{-n_{2} p}\left(1+n_{2} p e^{-2 i n_{2} p}\right\}=\beta_{1}^{\prime \prime}, \text { if } \mathrm{i}=\mathrm{j} \text {, for fraction defective } \mathrm{p}=\mathrm{p} 1
$$

$e^{-n_{2} p}\left(1+n_{2} p e^{-2 i n_{2} p}\right\}=\beta_{2}$ "', if $\mathrm{i}=\mathrm{j}$ ' for fraction defective $\mathrm{p}=\mathrm{p}_{2}$

The above equations cannot be solved easily. Hence, the solutions are obtained by using an iterative procedure. A computer program is written to solve the equations and tables are constructed to facilitate easy application at shaft floors

Table 1: Shows the Values for $n_{1}, n_{2}, k$ and i for the Mixed Sampling Plan Through AQL and LQL when $\left(p_{1}, \beta_{1}\right)$ and $\left(p_{2}, \beta_{2}\right)$ are Known. Assuming $\beta_{1}=0.99, \beta_{2}=0.01, \beta_{1}{ }^{\prime}=0.80, \beta_{2}{ }^{\prime}=0.0055$

\begin{tabular}{|c|c|c|c|c|c|c|c|c|}
\hline \multirow{2}{*}{$\mathbf{p}_{\mathbf{1}}$} & \multirow{2}{*}{$\mathbf{p}_{\mathbf{2}}$} & \multirow{2}{*}{$\mathbf{n}_{\mathbf{1}}$} & $\mathbf{k}$ & \multicolumn{6}{|c|}{ Value of $\mathbf{n}_{\mathbf{2}}$} \\
\cline { 5 - 9 } & & & $\mathbf{i}=\mathbf{j}=\mathbf{1}$ & $\mathbf{i}=\mathbf{j}=\mathbf{2}$ & $\mathbf{I}=\mathbf{j}=\mathbf{3}$ & $\mathbf{I}=\mathbf{j}=\mathbf{4}$ & $\mathbf{I}=\mathbf{j}=\mathbf{5}$ \\
\hline .001 & .01 & 20 & 33.69 & 170 & 152 & 156 & 125 & 100 \\
\hline .002 & .02 & 15 & 26.87 & 85 & 72 & 70 & 66 & 55 \\
\hline .003 & .03 & 14 & 25.47 & 77 & 60 & 56 & 45 & 34 \\
\hline .004 & .04 & 13 & 24.05 & 58 & 47 & 33 & 26 & 22 \\
\hline .005 & .05 & 12 & 22.62 & 46 & 33 & 27 & 26 & 22 \\
\hline .007 & .07 & 11 & 21.16 & 29 & 26 & 21 & 19 & 15 \\
\hline .008 & .08 & 10 & 19.68 & 26 & 21 & 19 & 15 & 13 \\
\hline .009 & .09 & 8 & 16.62 & 22 & 10 & 7 & 4 & 3 \\
\hline .010 & 10 & 4 & 9.837 & 10 & 7 & 4 & 4 & 3 \\
\hline
\end{tabular}

\section{Illustration}

Let $\mathrm{p}_{1}=0.007, \mathrm{p}_{2}=0.07$ and the corresponding probability of acceptance be $\beta_{1}=0.99, \beta_{2}=0.01$. Find the mixed plan with two-sided chain sampling plan as attribute plan for variance criterion when $\mathrm{i}=\mathrm{j}=3$

\section{Solution}

For $\mathrm{p}_{1}=0.007$ and $\mathrm{p}_{2}=0.07$, first stage sample size is $\mathrm{n}_{1}=11$

Given $\beta_{1}=0.99$ and the $1^{\text {st }}$ stage probability of acceptance is, $\beta_{1}^{\prime}=0.80$

From table 1 , the acceptance criterion is $k^{\prime}=21.16$ and the second stage sample is $n_{2}=21$,

When $\mathrm{i}=\mathrm{j}=3$ 


\section{CONCLUSIONS}

Hence in this paper, Mixed Sampling Plan with Two-Sided Complete Chain Sampling as attribute plan is developed for the variance by considering the results of past as well as future lots. Since the plan considers both the variable and attribute quality characteristics, it ensures more protection for the producer.

\section{REFERENCES}

1. SCHILLING, E. G.(1967), 'A general method for determining the OC of Mixed variable- attributes Sampling plans, Single sided specifications, SD known', Ph. D. Thesis, Rutgers - The state university, New Brunswick, New Jersey.

2. Clark. C. R (1955), “OC Curves for Chsp -1, Chain sampling plans”, Industrial Quality Control, 17(4), 10 - 12.

3. Frishman and Fred (1960), “An Extended Chain Sampling Plan”, Industrial Quality Control, 17(1), 10 -12.

4. Dodge. H. F and Stephens K. S (1966), “Some new chain sampling Inspection,” Industrial Quality Control, $23(2), 61$ - 67.

5. Kuralmani. V and Govindaraju. K (1993), "Selection of Conditional Sampling plans for given AQL \& LQL", Journal of Applied Statistics, 20(4), PP $467-479$.

6. SURESH K. K. and DEVAARUL S (2002), "Designing and Selection of Mixed Sampling Plans with Chain Sampling as attribute plan”-Vol.15, No: 1, pp. 155-160, Quality Engineering Journal, U. S. A.

7. SURESH K. K. and DEVAARUL S (2003), Mixed sampling plans for maximum allowable variance, Far East J. Theoretical Stat. India, Vol 9, issue 2, pp 133-141 